\title{
Jewellery, the urban milieu and emergence
}

\author{
Jacqui Chan
}

\begin{abstract}
This paper traces a practice-led enquiry into the question of how jewellery - as a practice and an artefact - can engage the city in terms of emergence. While jewellery is often understood to have a decorative, symbolic or communicative function, this research explores jewellery's immersion in and emergence from the urban context. Coming from a background in architecture, I am interested in approaching the city as an extended site for jewellery: both the lived situation within which jewellery is worn, and a rich material resource for its production; and, where jewellery is sited between mobile bodies and these urban surroundings.

This practice-led research adopts the analogy of the saprophyte - an organism that decomposes organic matter and recirculates nutrients through its ecosystem - as a logic for exploring how making and wearing can feed off and back into the material ecology of the city. This paper shares four projects that respond to specific urban situations - Melbourne, Ramallah (Palestine), Chinatown (Melbourne), and Christchurch discussing what emerges within each situation, and what these projects offer for thinking about jewellery - as a practice and an artefact - and its relations with the city.
\end{abstract}

\section{Introduction}

How can jewellery - as a practice and an artefact - engage the urban milieu in terms of emergence?

This question has been the focus of a series of projects that explore jewellery's relations with the city. While jewellery is often understood to have a decorative, symbolic or communicative function, this practice-led research explores jewellery's immersion in and emergence from the material ecology of the city. ${ }^{1}$ Coming from a background in architecture, I see the city as an extended site for jewellery - both the lived situation within which jewellery is worn, and a rich material resource for its production - with jewellery sited at the mobile interface between bodies and their urban surroundings.

In questioning how jewellery practice might engage the urban milieu I adopt the biological analogy of the saprophyte (which I will introduce below) as a logic for exploring how making might feed off the urban context and feed back into it through wearing. This inquiry is also influenced by the concept of emergence a concept from complexity theory that describes the unpredicted appearance

1 This research is part of a practice-led PhD at RMIT University, provisionally titled 'Jewellery in the Urban Milieu: Explorations in Emergence' (to be completed in 2013). 
of new and novel features within systems. This has enabled me to approach practice as a series of relations and processes that encourage unplanned outcomes, and to foster the attitude of not-knowing-in-advance.

This paper begins by introducing the question of jewellery's relation with the city and outlines the concepts of the saprophyte, emergence and the urban milieu that inform the practice. It then charts the emergence of this practice through four recent projects - that respond to specific urban situations: Melbourne, Ramallah (Palestine), Chinatown (Melbourne), and Christchurch; discussing what emerged through the projects for practice and for thinking about jewellery's relations with the city. Through these projects, both making and wearing are explored as processes for engaging with these situations in ways that open up new possibilities. These yield not only jewellery artefacts, but new relations with and experiences of the city, and insights into jewellery's potential to activate relations between bodies and their urban surroundings.

\section{Jewellery and the city}

My thinking about jewellery is influenced by my background in architecture; where I have come to see architecture as a dynamic material and social formation that engages with specific contexts, bodies and forces. Architecture is not merely a combination of form and matter, but is animated by day-to-day rhythms of inhabitation, weather and gradual processes of change over time. This influences my interest in jewellery's relation to specific contexts, and how it performs in the world - particularly in terms of its sites, mobility and how it forms connections. Furthermore, jewellery's site between the body and the city suggests its potential to mediate relations between people and their urban surroundings.

Coming from Aotearoa / New Zealand, I see my interest in jewellery's relationship with the city as extending a pivotal question within New Zealand contemporary jewellery of how to engage 'the local'. Since the international exhibition Bone, Stone, Shell of 1988, contemporary jewellers have looked to the local context of Aotearoa and the Pacific - rather than Europe - in an effort to redefine Aotearoa as a bicultural rather than colonial nation. The tendency has been, however, to engage the local either at an overarching level of ideas of cultural identity, or to depict idyllic natural environments distanced from the realities of urban life. This paper presents explorations of how jewellery practice might actively engage the often less idyllic conditions of the urban context through both making and wearing.

In the context of more recent contemporary practice, the practice that emerges from this inquiry also coincides with what might be described as expanded jewellery practices. With strategies such as street performance, public jewellery installations, alternative modes of distribution, community making workshops, and interviewing wearers about jewellery, such practices expand beyond 
contemporary jewellery's traditional focus on the crafted artefact, the studio and the exhibition. Increasingly, jewellers are also concerned with relations formed around or through jewellery between makers, wearers, communities and places, often in connection with current social, political or environmental issues. ${ }^{2}$ Within this burgeoning field the projects presented in this paper contribute by developing a practice that both responds to specific urban situations through making, and explores how the experience of wearing might affect relations between wearers and those surroundings.

\section{The saprophyte}

To explore how jewellery can engage the urban milieu, the saprophyte is adopted as an operational analogy. This term refers to organisms - such as some fungi - that live by decomposing organic matter and releasing nutrients to their ecosystems. They embody an embedded and reciprocating relationship with a surrounding ecology based on transformative material processes.

I first encountered the term saprophyte as a proposition for architecture in an editorial in Domus, 'In praise of saprophytes', in which Flavio Albanese proposed the saprophyte as a model for a 'truly contemporary architecture':

A crossover, an unstable and impermanent discipline, a saprophytic machine capable of incorporating and metabolising at different levels the physical and cultural materials of today's space, in order then to put them back into the cycle of life reassembled in different sequences. (2008)

Albanese speculated that the concept of the saprophyte might shift architecture 'from production and accumulation (implying the erection of new monuments) to the interception and transformation of objects and concepts already present in our environment ... (where) its aim is to find solutions and contexts not yet thought of or tested' (2008).

I have connected with this proposition in jewellery because it offers a way of linking making practice with an ecological conception of the city, proposing that jewellery might transform things already in circulation and enable their recirculation through wearing. Additionally, by instigating nutrient-cycling, the saprophyte embodies the potential for tiny, seemingly insignificant entities such as jewellery - to have a significant bottom-up effect on larger systems.

2 A short, and by no means exhaustive, list of practitioners working in this area of the field include Mah Rana (United Kingdom), Suzanne Pietzsch (Germany), Susan Cohn (Australia), Roseanne Bartley (New Zealand, Australia), Yuka Oyama (Japan, Germany), Gabriel Craig (United States), Caz Guiney (Australia), Areta Wilkinson (New Zealand), Kristin D’Agostino (United States, New Zealand), Marie Erl (New Zealand), Ted Noten (The Netherlands), Ana Cardim (Portugal), Ethical Metalsmiths (United States). 


\section{Emergence}

A key feature of the saprophyte is its capacity to produce something new within a given situation and, as a result, the concept of emergence has also been central to how I approach these explorations. Within complex systems, emergence refers to the appearance of new or novel properties and capacities through the interaction of multiple parts or evolution over time. ${ }^{3}$ Emergence has been used to describe a plethora of complex interactions, from ant colonies and weather formations to economic markets and artificial intelligence. Although emergence is arguably a feature of all creative practices, actively foregrounding emergence has enabled my explorations in making and wearing to become oriented towards open-ended processes that encourage unanticipated outcomes and unfold through an ensemble of relations. In positioning such a practice as research, the concept of emergence also fosters an attitude of not-knowing-in-advance, where experimentation sets processes in motion to see what emerges for both practice and thinking.

\section{The urban milieu}

Throughout this paper I use the term 'urban milieu' to evoke the dynamic ecological dimensions of the city as a temporal-spatial situation in which we are enmeshed. Whereas terms such as 'the city' or 'the urban environment' emphasise the physical terrain or architectural structures of the city, 'milieu' invokes the surrounding or medium in which things are immersed. In biology it names a block of space-time relative to the living organism and is the basis of the organism-plus-environment unit of survival; ${ }^{4}$ while, in French geography, the term was introduced by Vidal de la Blanche to study how human groups adapt to and modify their natural surroundings (Mercier 2009). In particular, for this practice, Jakob von Uexküll's notion of the umwelt - the behavioural milieu or bubble-world shaped by an organism's sensory capacities and functional needs (Uexküll 2001; 2010) - has been useful for thinking about the experiential relations between the body and the city, and how processes and individuals reciprocally are affected by and have the capacity to affect a surrounding milieu. The term 'urban milieu', therefore, positions the city as a collective milieu - a milieu of milieus - that is produced and evolves in relation to its inhabitants, while being part of vaster geological and ecological systems.

3 The notion of the 'new' or 'novel' refers to the appearance of properties, capacities or a level of coherence not formerly evident in a system or its parts. As DeLanda writes, what is produced is 'not new in the absolute sense that something emerges that has never existed before but only in the relative sense that something emerges that was not in the interacting entities acting as causes' (DeLanda 2011: 2).

4 In Philosophie zoologique (1809) Lamarck proposed that the environment determines the adaptive evolution of organisms, contrasting Charles Darwin's later theory that evolution is primarily affected by relations between living things (genetics and natural selection) (Canguilhem 2001: 12-14). 
I will now discuss four projects that have explored the analogy of the saprophyte as logic for how jewellery can engage the urban milieu in terms of emergence. The projects have involved phases of milieu-explorations, material-transformations and wearing-projects. I will briefly discuss key aspects from each project in order to convey the overall trajectory of the research.

\section{Urban Metabolism Series, Melbourne, 2009-ongoing}

Urban Metabolism Series was an early phase of the PhD, based in Melbourne, where I began exploring the saprophyte as a diagram, ${ }^{5}$ or set of procedures, for making. This involved processes of exploring the urban milieu, gathering materials and transforming them into new configurations. This project initiated questioning of relations between jewellery, the body and the city, and explored making as a process of emergence.

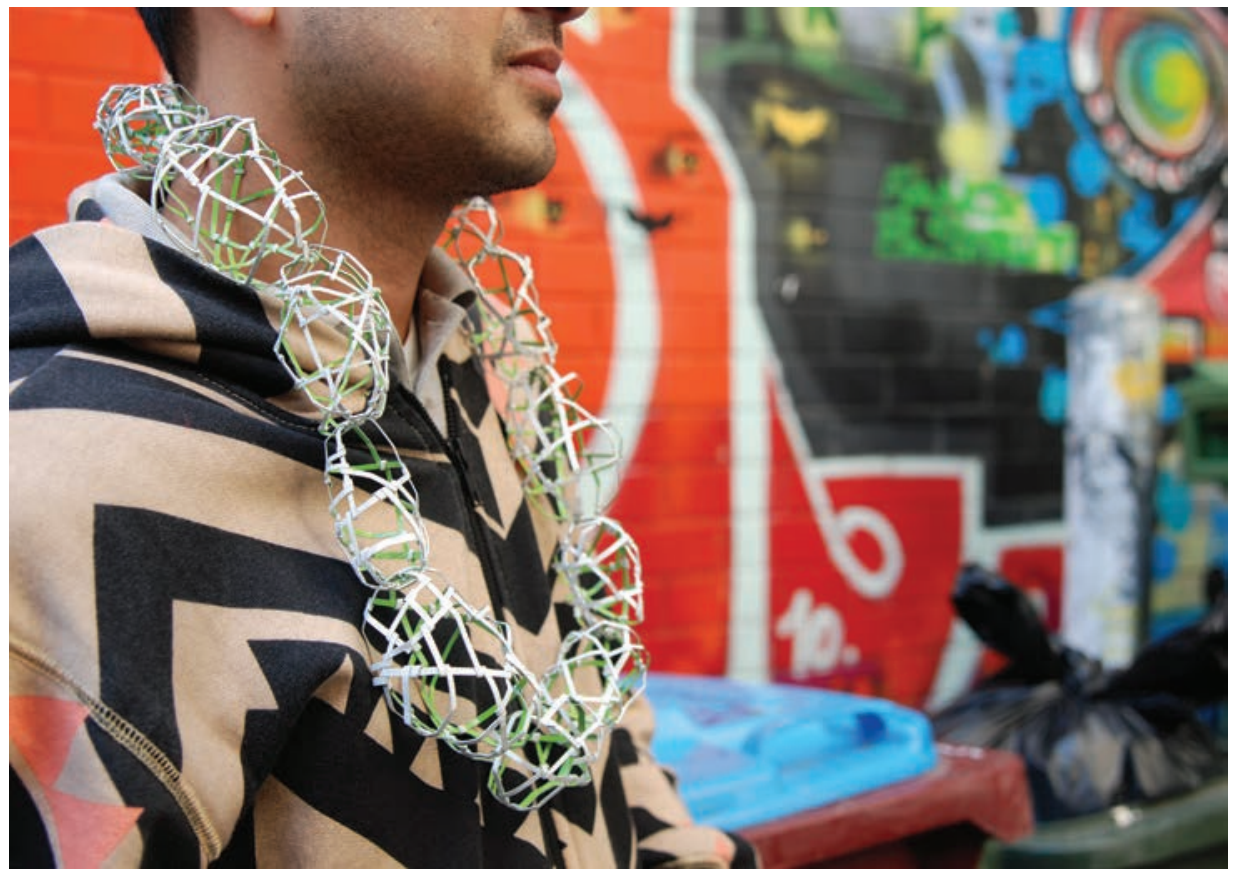

Figure 1. Urban Metabolism Series, 2009.

Photography: Jacqui Chan

5 By 'diagram' I mean a set of generative operations that encourage the emergence of new possibilities. For example, in relation to the paintings of Francis Bacon, Gilles Deleuze describes the diagram as a strategy for ridding the blank canvas of clichés through random 'nonrepresentative, nonillustrative, nonnarrative ... asignifying' marks through which 'new possibilities of fact' (and the figure) emerge (Deleuze 2004: 71). 
From the outset, the process of retrieving materials from alleyways, dumpsters and construction sites allowed me see the city as a material ecology: a continual flow of materials - food, products, waste, construction, demolition, (bodies) - into which practice might intervene, divert, transform and circulate anew. Approaching the city as a material ecology invoked political scientist Jane Bennett's view that 'humans are always in composition with nonhumanity, never outside of a sticky web of connections or an ecology'; describing an ecology as 'a dynamic flow of matter-energy that tends to settle into various bodies, bodies that often join forces, make connections, form alliances' (2004: 365). In A Thousand Years of Nonlinear History Manuel DeLanda also highlights a material connection between the city and the human body, on a more evolutionary timescale. He describes cities as 'human exoskeletons' that have emerged as part of the evolution of the human organism: just as their internal counterparts, bones, enable mobility of the body, this external mineralisation of the body (bricks and mortar) enables and controls movements of matter-energy, such as food, commodities and bodies (DeLanda 1997: 27-28).

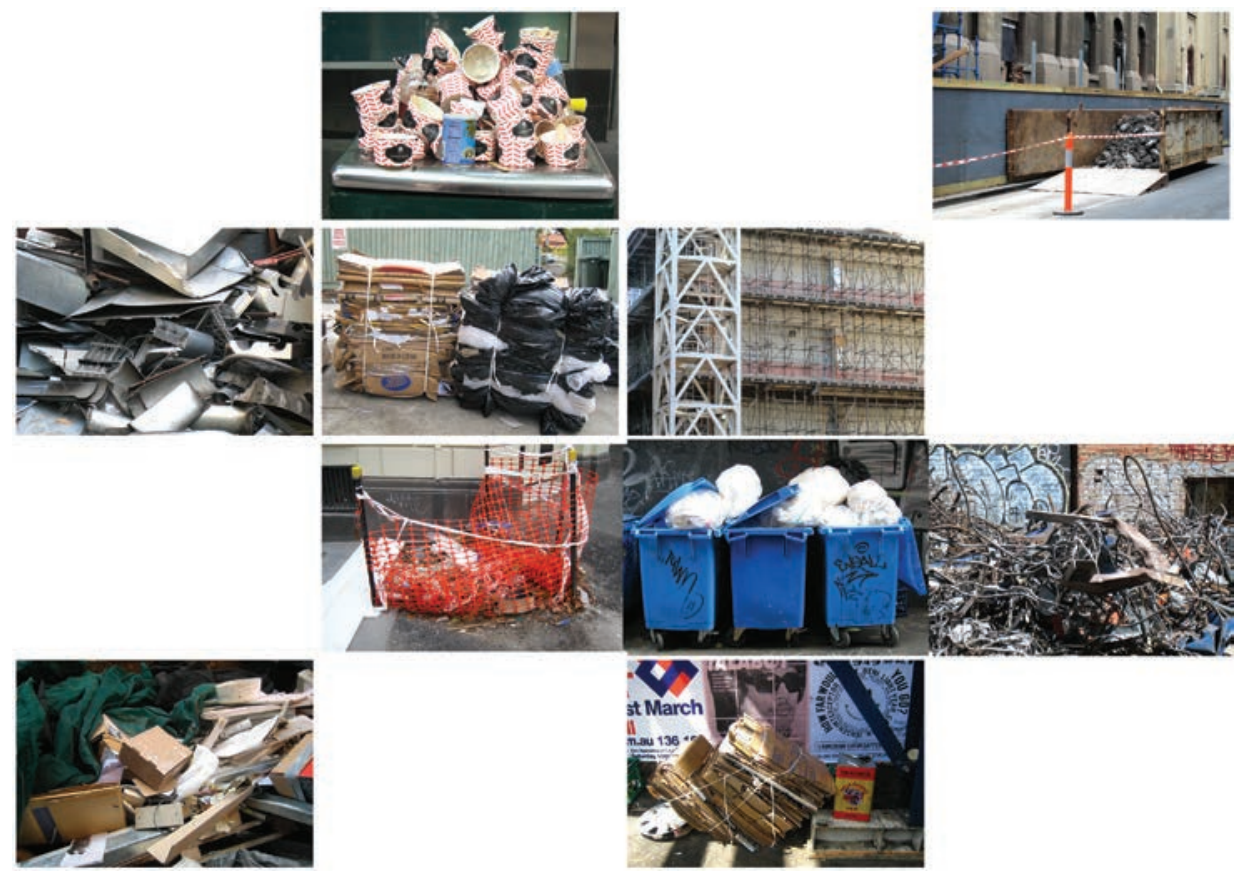

Figure 2. Urban Metabolism Series, 2010.

Photography: Jacqui Chan 
Exploring the city on foot also drew attention to the experiential and peripatetic relation between the body and the city, and jewellery's site between them. As Elizabeth Grosz reminds us, bodies and cities are not discrete entities but involve:

assemblages or collections of parts, capable of crossing the thresholds between substances to form linkages ... (whose) interrelations involve a fundamentally disunified series of systems, a series of disparate flows, energies, events or entities, bringing together or drawing apart their more or less temporary alignments. (Grosz 1995: 108)

With respect to these dynamic relations between the body and the city, I was particularly interested in the brooch as one of the most public forms of jewellery, visibly sited/sighted on the body, being relatively free of gender associations; and having a degree of autonomy as a material thing that attaches to the body - without its form being determined by it (like a ring or a necklace) - to produce an encounter.

In sketching the spatial relation between the body-as-site and the extendedsite-of-the-city, the brooch occupied the interstitial zone between the matter of the body and the city, and I was curious to articulate and mediate relations between them. If, as Georg Simmel (1950) might insist, jewellery traces a vector of expression from the wearer toward the world, I questioned how this vector might be reversed to approach jewellery as a thing through which the materiality of the city becomes expressive on the body, drawing attention towards one's surroundings rather than one's self.

In the making, the saprophyte suggests a set of procedures for transforming materials in a way that explores emergence. The aim was to find processes for metabolising and reassembling materials through which new formations could grow. This began by testing a range of techniques to break materials into components, and the challenge was not to simply aggregate these into new assemblages - as I did with early experiments, where fragments of various materials were connected via a base structure - but to find ways of manipulating the components to transform them into unplanned self-supporting structures.

The ongoing Urban Metabolism Series developed a self-generating, weaving-like process involving fine strips joined together by a repeated, folded connection. Folding offered a simple action through which the formal, spatial and material properties (e.g., hardness or work failure) of a piece of material could be transformed and reconfigured. This process leant itself to sheet metals - such as commercial cooking oil cans, and off-cuts of galvanised steel and flashings - whose malleability and strength retained the folds and enabled folding to be used as a joining system. 


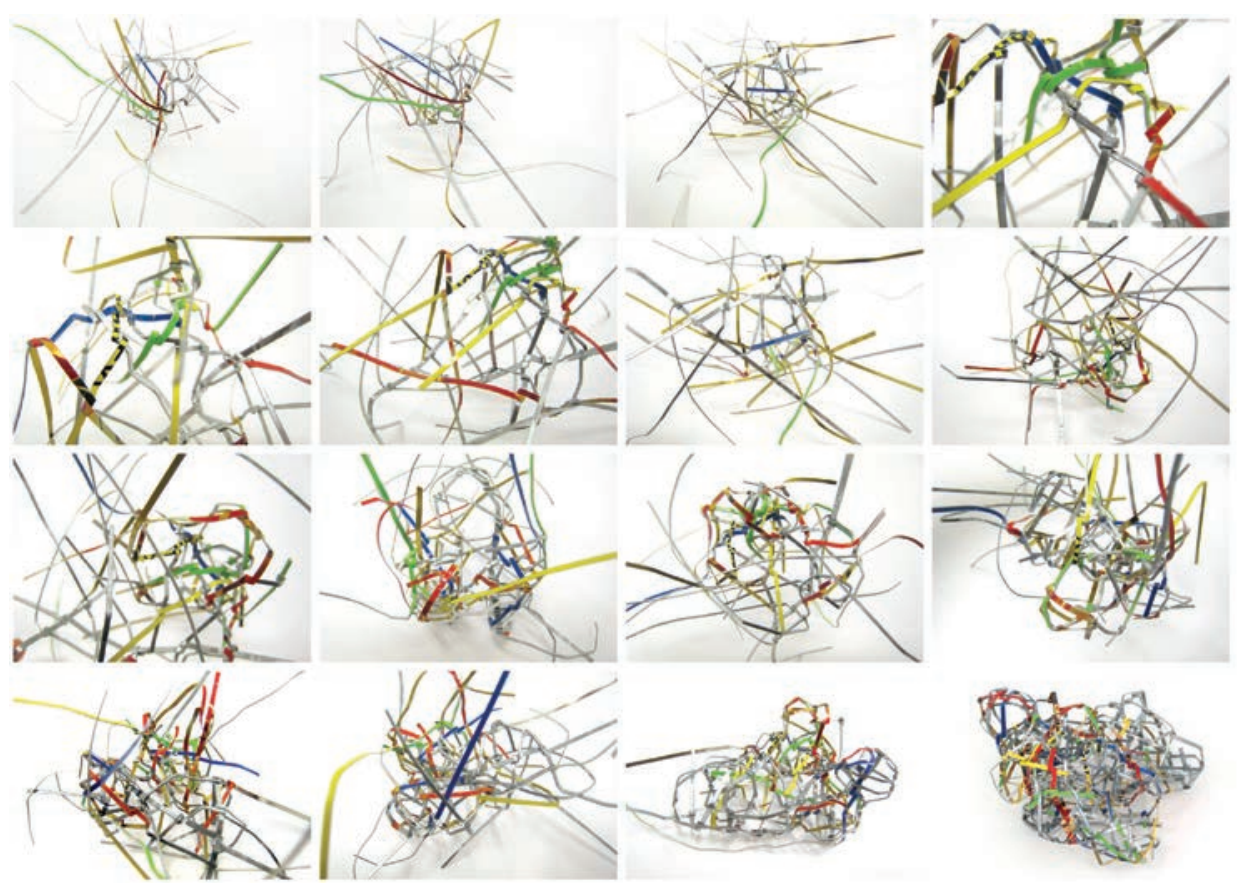

Figure 3. Urban Metabolism Series, making process, 2009.

Photography: Jacqui Chan

The process of formation was guided by a simple rule that each strip would be folded to meet another in space, at a precise angle (usually 30 degrees) where it could be wrapped over, down, and back up around the other to be crimped into place neatly beside itself. This repeated action (and the pragmatics of guiding each strip in and out of the structure without damaging its surface) determined where folds were made, which strips could be joined, and the proximity of connections. And, from a chaotic splay of strips, unplanned, nonrepresentational formations gradually crystallised.

What interested me was the process's distinctive relational dynamic where, to allow something new to emerge I needed to relinquish control over the process. As Pia Ednie-Brown observes:

emergence casts the designer out of the role of a controller - or centralised commander - and into a more participatory, guiding role. It involves a mode of composition or creative practice that amplifies and highlights the act of entering into dynamic relation, negotiation and interaction. (2008: The Pandora's Box of Emergence para. 2)

Rather than coercing materials to fit a pre-defined form or idea, making became a process of formation where form emerged through the cooperation of material, 
tools, hands and eyes - a dynamic that resembled what John Protevi (2006) describes as transverse emergence, where unlike entities form assemblages that enable new properties and capacities to emerge. ${ }^{6}$
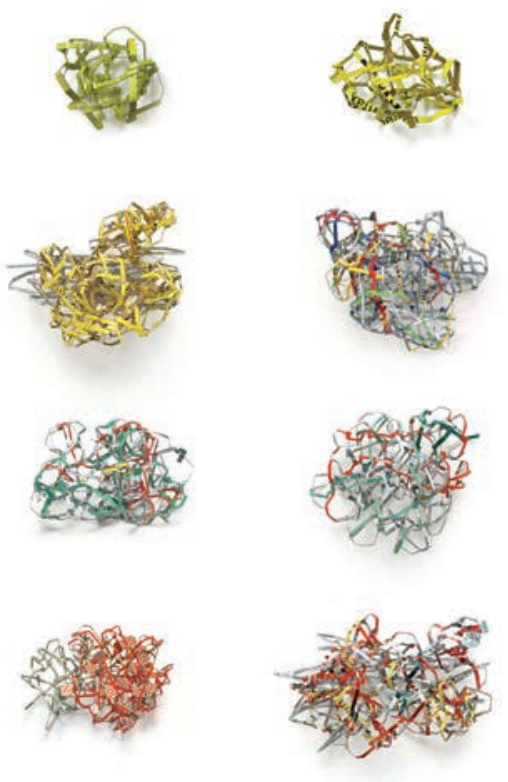
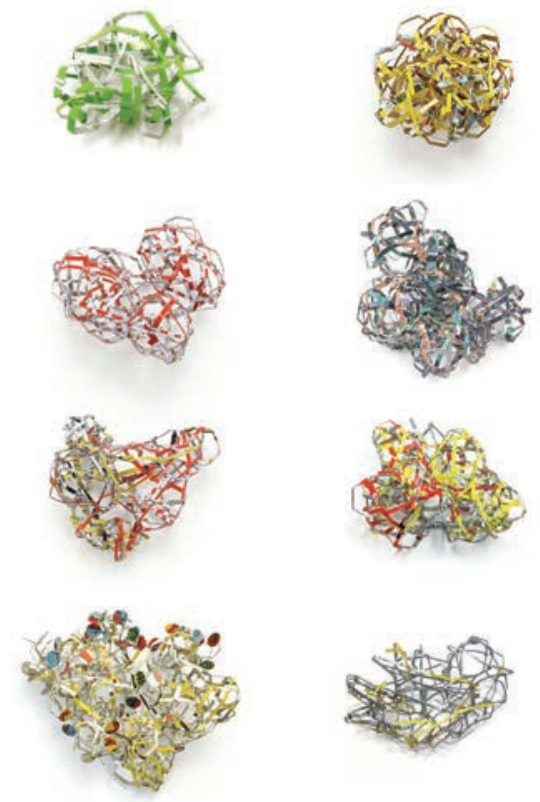

Figure 4. Urban Metabolism Series, brooches, 2009-2011.

Photography: Jeremy Dillon and Jacqui Chan

The resulting open-weave structures did not represent the city but indexed their process of transformation from materials of the city, metabolised and attached to the body. Even off the body, the brooches enticed interaction. The repeated folds created an alternating rhythm between the front and reverse sides of the strips, and facets, off which the light glinted, causing it to be turned before the eye to make sense of the form. The potential to peer into their interior also shifted the apparent scale of the structures, evoking multiple associations: graffiti, veins of the body, eco-buildings, subway systems.

6 Whereas studies of emergence often concentrate on synchronic emergence between like elements - such as flocking behaviour in birds or hydrogen and oxygen atoms behaving as water - or diachronic emergence - or evolution - of new forms over time, Protevi adds a third form of emergence that connects with Deleuze's concept of assemblage where connections may form 'transversally' between different organisms, subjects or technologies, as in Deleuze and Guatarri's example of horse-man-stirrup assemblage that in sedentary societies enabled agriculture, and in nomadic societies enabled war (Protevi 2006: 28, citing Deleuze and Guattari 2004: 440). This was useful for thinking about both making and wearing as relational processes, through which new properties or capacities might emerge. 


\section{Situation Palestine, Ramallah, 2010}

In 2010 my partner took a contract in Ramallah, Palestine. This gave me the opportunity to spend six months there, and to explore this process in a new situation.

This period of work highlighted the relation between practice and its surrounding milieu. The saprophyte offered a logic for working-in-the-midst of this situation as an outsider, welcoming its potentials and constraints as forces on the making. Rather than presuming to understand the situation in advance - to represent or critique it - contingent understandings arose through practice.
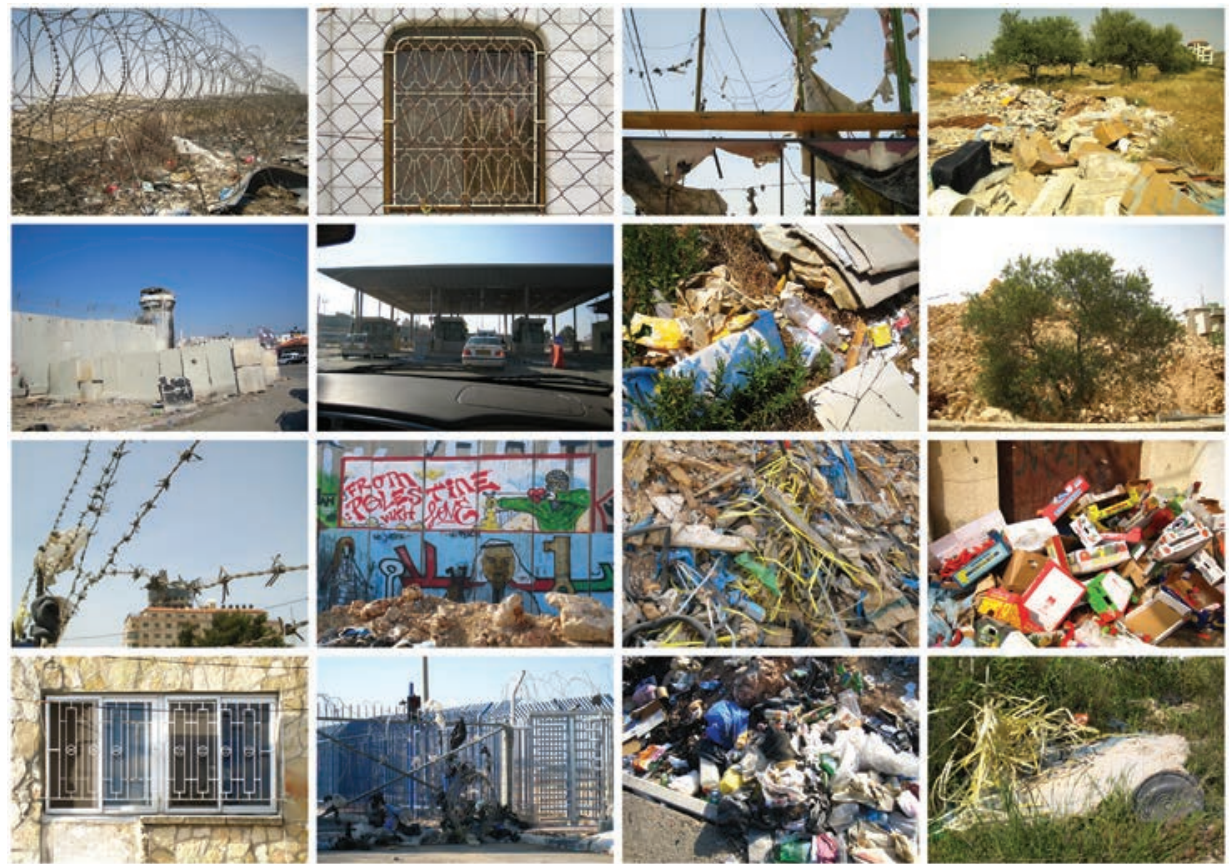

Figure 5. Context photos, Ramallah, 2010.

Photography: Jacqui Chan

Exploring the city and gathering materials, my lasting impression was the contrast between the recurring boundaries, in place to restrict the movement of bodies, and the vibrant and unruly liveliness at the margins. I was attracted to empty sites where the city's flows of materials accumulated and were colonised by rampant weeds, and was struck by the explicit tension between the human and nonhuman aspects of the situation, and the paradox of fighting over the land-as-territory while the environment fell into disrepair.

In relation to the intensely stimulating and often tense circumstances in the street, I became conscious of the spatial divide between the studio and surrounding context. Whereas the logic of the saprophyte suggested full immersion in a 
surrounding milieu - for instance, making in the street - in Ramallah, the studio formed a milieu within the extended situation that sheltered a space of experimentation within which selected elements of the situation might be gathered together and processed into something new.

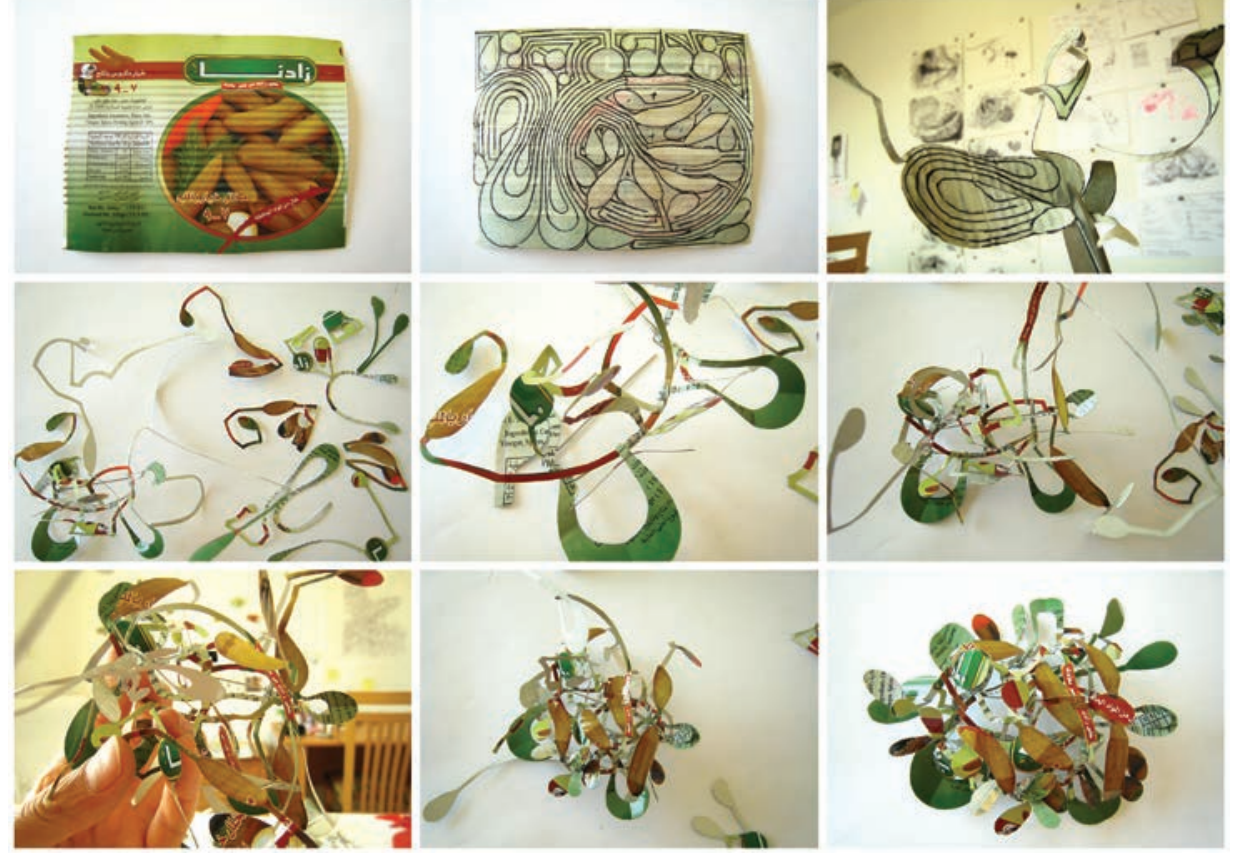

Figure 6. Situation Palestine, making process, 2010.

Photography: Jacqui Chan

For the making process, Ramallah presented a new set of constraints, which forced adaptation. The scarcity of 'quality' rubbish, for instance, forced an economy of utilising every inch of the found materials to construct the largest possible structures, while being limited to basic hand tools - rather than workshop machinery - allowed for more intricate components; which culminated in a series of brooches woven from olive and vegetable cans.

While making, however, I was caught in a dilemma of exploring emergence in the studio while supposedly trying to 'engage' the urban context around me as the making neither represented the urban context, nor took place within it. But this allowed me to realise that this divide between the making process and the extended situation was vital, for it enabled something new to emerge - a third thing from this encounter between the saprophytic logic and the potentials of this urban context. Moreover, the incompatibility between practice and this milieu forced adaptation that yielded new possibilities. 

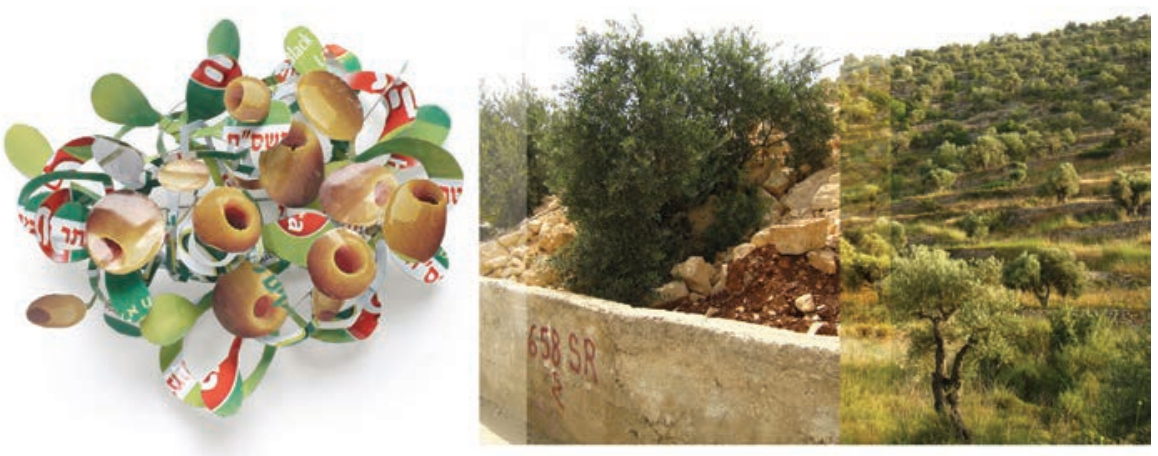

Figure 7. Situation Palestine, olive brooch, 2010.

Photography: Jeremy Dillon (left) and Jacqui Chan (right)

Surprisingly, despite avoiding representation, the resulting brooches manifest aspects of the surrounding social and political situation. Olives, for instance, are a Palestinian symbol of rootedness to the land, and the cans evoked the struggle to retain land in the face of the encroaching wall and Jewish settlements. ${ }^{7}$ They also reflect the contradictions of the political situation, with all the brandnames on the cans being Israeli. The tangled structures also resembled the city's complex, maze-like streets, its undulating terrain and vigorous weeds. This recalls Francis Bacon's diagrammatic approach to painting, where figures emerge through random, nonrepresentational marks, producing resemblance through 'accidental and nonresembling means' (Deleuze 2004: 69).

\section{Material Migrations, Chinatown Melbourne, 2011}

Material Migrations was an opportunity to explore the full life cycle of the saprophyte, engaging the site of Chinatown through making and wearing. This project grew from an invitation to take part in an exhibition at the Chinese Museum and allowed me to explore how the saprophyte might offer a distinctive mode for engaging Chinatown - beyond its dominant theme of cultural identity.

7 The separation wall is often encroaches onto the Palestinian side of the 'green line', and results in the up-rooting of trees or confiscation of whole olive groves. Israeli settlers, illegally occupying hilltop compounds in the West Bank, have also targeted olive crops, either harvesting olives ahead of the farmers, shooting farmers at harvest time or, in some cases, burning the trees. 


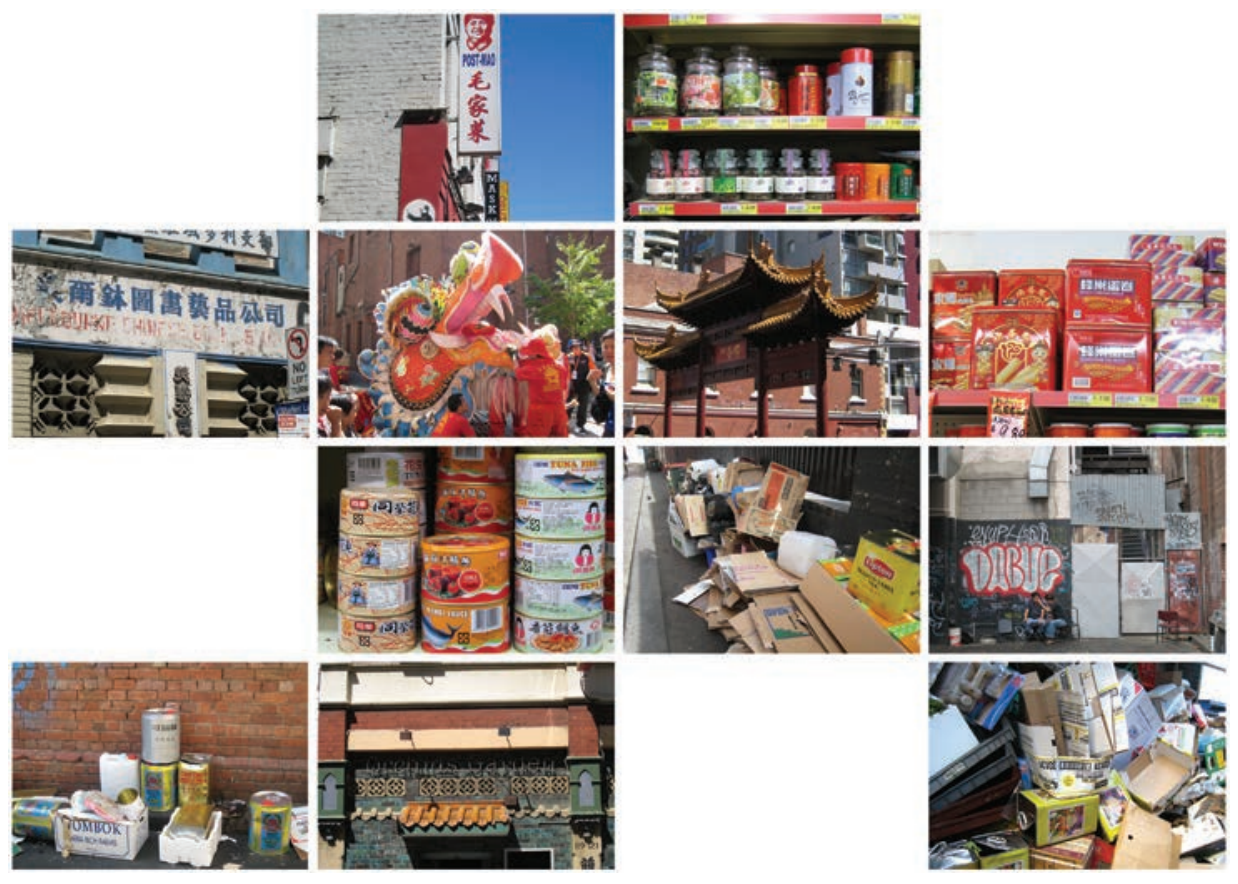

Figure 8. Context photos, Chinatown, 2011.

Photography: Jacqui Chan

The title reflects my desire to engage Chinatown from a material perspective. I noted how materials gathered from restaurant refuse and Chinese supermarkets embodied connections with distant places - through their histories of extraction, manufacture, transportation - as well as the day-to-day flow of products. These trajectories also echoed the routes of migration that have historically composed Chinatown. I therefore came to approach Chinatown as a confluence of flows of materials and bodies linking a network of places: flows into which practice might intervene, transform and recirculate anew.

The project involved making 35 brooches and giving them away to wearers (to keep) in exchange for them wearing the brooches in daily life around Chinatown or further afield, noticing aspects of their surroundings to which the brooches drew attention, and documenting this with photos. ${ }^{8}$ The photos were returned by email and added to an accumulating video screened in the museum and on the project blog (http://materialmigrations.wordpress.com/).

8 These brooches were smaller versions of the Urban Metabolism Series open-weave brooches, and incorporated more intricate 'blanked' (hand die-cut) components based on the packaging graphics. I specifically wanted to test the affect of this kind of open structure on people's perception of the city, so there was a degree of consistency between the brooches in order to focus on the range of people's responses. 


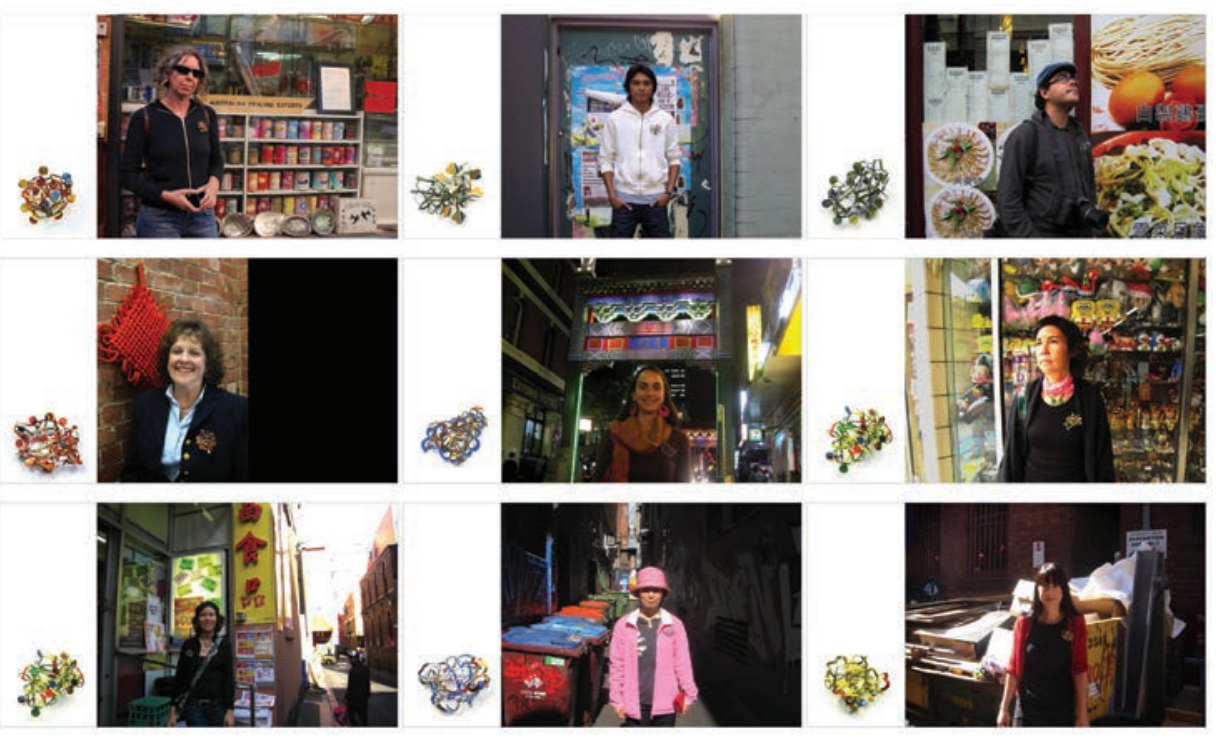

Figure 9. Stills from Material Migrations video, 2011.

Photographs provided by wearers

Like a saprophyte feeding nutrients back into its ecosystem, I was interested in the flow-on effects of the brooches in the day-to-day act of wearing. I see wearing as a process of emergence, a coming-together of the brooch, body and surroundings from which new relations or experiences might emerge.

The wearing project made the unusual proposition to wearers that jewellery might activate relations with one's surroundings. On the one hand, the project was shaped to foster an open 'see what happens ...' attitude, to see what might emerge through wearing; while, on the other hand, I needed to coax people's attention towards relations with their surroundings - rather than, for instance, continuing to focus on self-expression and identity or social interactions, which are more often associated with jewellery. University ethics procedures also had a positive impact on shaping the project, requiring that detailed instructions be distributed to participants which carefully communicated the central proposition of the project.

The project yielded diverse responses. Many went beyond my own interests in the material ecology of the city, generating new thinking about jewellery's relations with the city and alerting me to challenges of this way of working. Responses ranged from what one wearer described as a lens for seeing a familiar place in a new way, to performative narrative responses.

The project also proliferated a wealth of material (photos, email comments and interviews) that challenged me to find ways to discern and articulate what emerged, in a way that valued its multiplicity - rather than shaping it to fit 
initial intentions or analysing it into patterns. My first instinct was to identify all the types of connections captured in the photos, but this analytically dissected the wearing experience into discrete parts and said nothing about the affect of wearing. So, instead, I processed the material saprophytically by cutting up and reconfiguring the visual material, to create an intensive mapping of the project's affects. ${ }^{9}$ This collage-process allowed me to think beyond the static subjectobject relations captured by individual photos, and consider how the duration of wearing activated a series of connections with diverse things that together composed a new impression of the city. From my own experience, it was as if the brooch attuned me to a new spectrum of my surroundings, making visible a series of visual, material and structural connections that composed a new impression of the city.

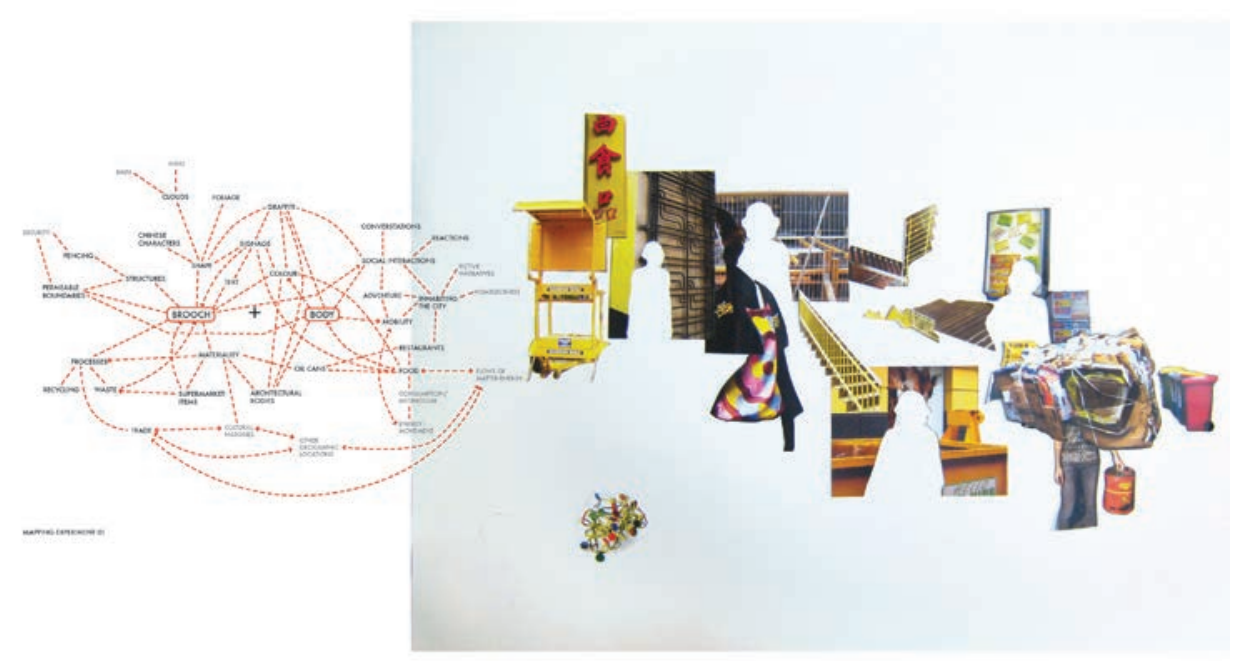

Figure 10. Material Migrations mapping process, 2011.

Photography: Jacqui Chan

I also learnt from things that contradicted my proposition. For instance, some wearers still focused on the social dimensions of the project: focusing on the idea of the gift; relations between maker and wearer; or belonging to a group surprising, since there was no interaction between participants. Some wearers also described it as a 'relational project', which highlighted the difference between my conception of relations and those promoted by 'relational art'. ${ }^{10}$ Whereas notions of sociability, conviviality and exchange, popularised in Relational Aesthetics (Bourriaud 2002), imply inter-subjective relations between already formed individuals, the saprophyte suggests an ecological model of

9 Deleuze's concept of affect refers to a body's capacity for affecting and being affected. As an example, a boy lists the affects of a horse pulling a cart: 'to be proud, to have blinders, to go fast, to pull a heavy load, to collapse, to be whipped ...' (Deleuze 1992: 626).

10 Bourriaud defines relational art as 'art taking as its theoretical horizon the realm of human interactions and its social context, rather than the assertion of an independent and private symbolic space' (2002: 14). 
relations as a dynamic relational field through which things emerge and are sustained over time. Rather than starting with subjects that then inter-relate, relation is a primary condition through which individuals or things become individuated, both through sets of relations between clusters of pre-individual elements, and relations with other things. Moreover, whereas relational art often concerns relations between people rather than material artworks, this project concerned the capacity of jewellery-as-a-thing to activate relations - and relations not only between people, but with the nonhuman world around them.

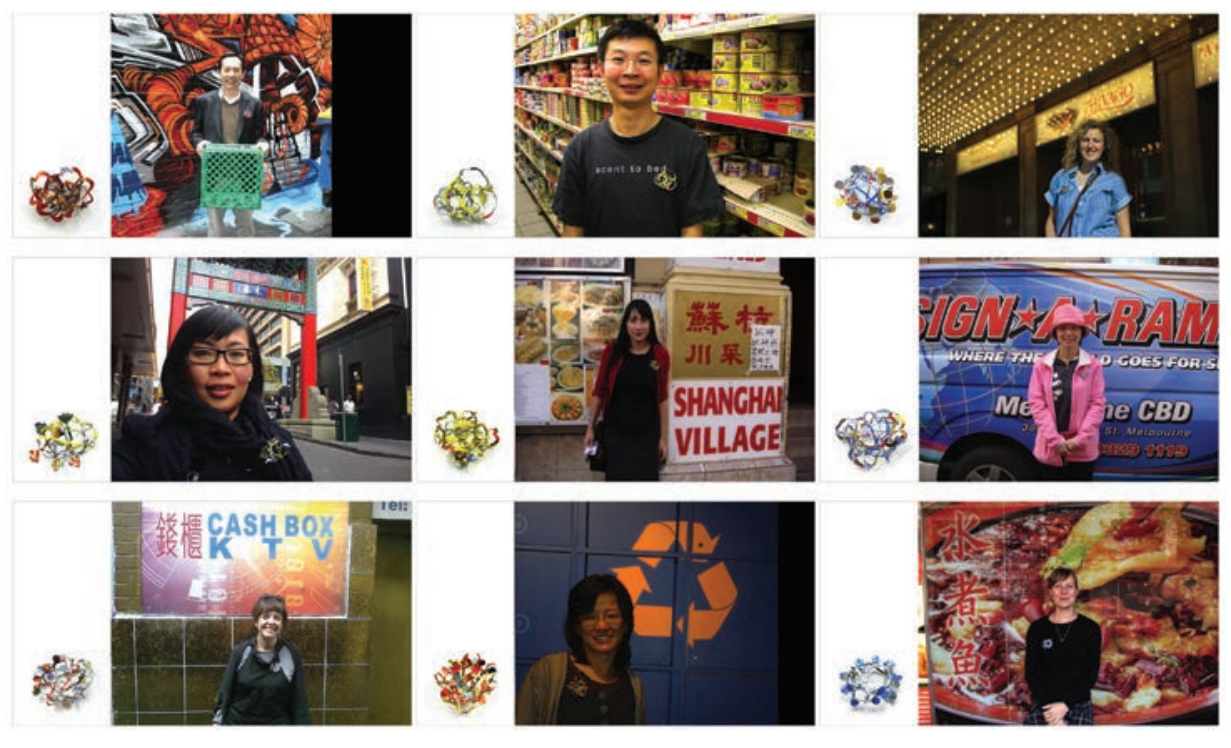

Figure 11. Stills from Material Migrations video, 2011.

Photographs provided by wearers

I also learnt that the photo composition I requested shifted people's attention from their surroundings back to themselves. Participants were asked to take photos in landscape format, with the upper half of the body centred in the image, clearly showing the surroundings and the brooch. I hoped this consistency would allow the singularity of the relations within each image to become apparent. This focused attention on a particular scale of the city - architecture, signage, vehicles, dumpsters - however, and maintained a physical distance between the body and surroundings (which became a backdrop). The act of taking this kind of photo also made some wearers feel self-conscious or like tourists; once again diverting attention back to themselves.

Compiling the images into the video, I hoped to encourage viewers to also notice connections between the brooch and the urban context, however, the presence of the face in the image, by habit, drew viewers' attention back to the identity and personality of the wearer. These observations showed that to 
explore alternative propositions about wearing - such as activating relations with our surroundings - it is equally important to find ways to circumvent people's tendencies to focus on the personal and the social.

\section{Host A Brooch, Christchurch, 2011}

Host A Brooch was an opportunity to expand on these previous projects and work within the post-earthquake situation of Christchurch. This project grew from an invitation to me to exhibit at a local jewellery gallery, The National. At the time, following the September 2010 earthquake, I was intrigued to respond to an urban milieu in a state of transition, and suggested a project that engaged to the city through making and wearing. The major February 2011 earthquake struck, however, leaving the gallery out of action in the 'red zone'. But, in spite of these challenging circumstances, gallery director Caroline Billing was determined to continue, and the project evolved into a more public format.

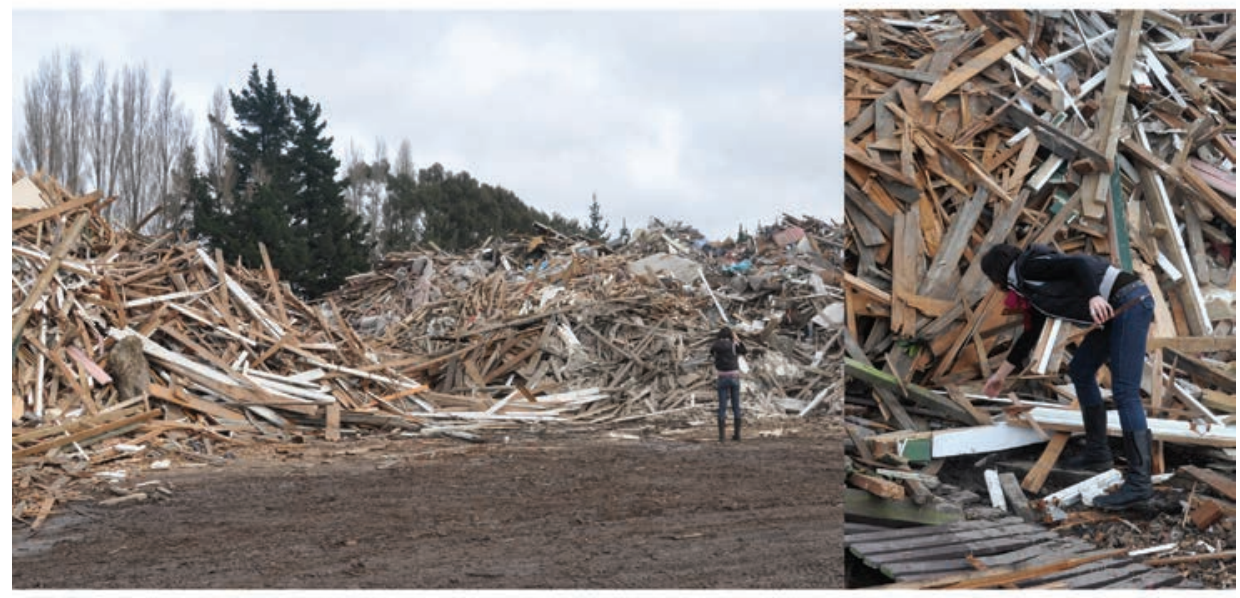

Figure 12. Gathering materials, Christchurch, 2011.

Photography: Caroline Billing

Initially I hoped to gather materials from demolition sites dotted throughout the city, but this was hampered by a mandate preventing waste materials being taken without permission from landowners. As a result, we followed laden trucks to demolition yards on the outskirts of the city. Encountering vast mountains of debris and rubble, we were confronted with the city's materiality and explicit processes of transformation. Alongside continual aftershocks, this was a reminder of the city's place within wider geological and ecological systems. The giant piles of demolished timber, in particular, evoked multiple timescales: the human stories of former buildings, geological timeframes, and the timber's former life as the region's forests. Here, what previously felt like a loose metaphor, the idea of the city as 'material ecology' was a palpable reality. 


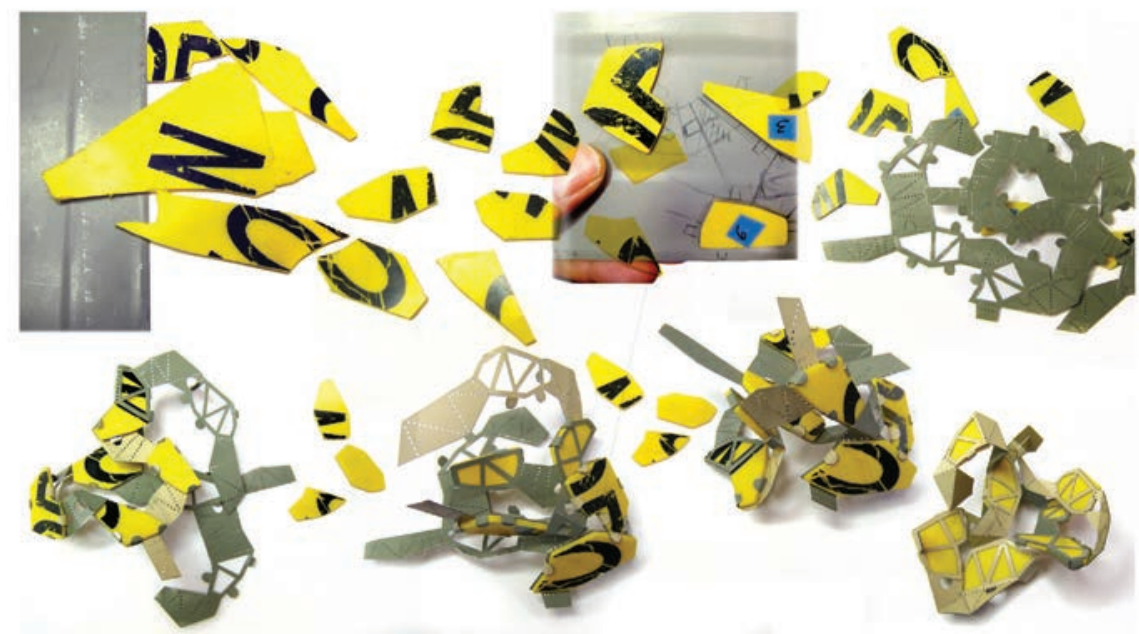

Figure 13. Host A Brooch, making process, 2011.

Photography: Jacqui Chan

The saprophytic making process was crucial to this project, dealing with a diverse range of materials: barrier mesh, parts of appliances, burnt floorboards, electrical cabling, road cones and rubble. A group of 16 brooches were made, once again by breaking materials down into components and using connecting systems that allowed them to grow into new and unplanned formations. Within this context, processes of remaking and reassembly pointed poignantly towards the city's renewal. I hoped the brooches would express a process of transformation, rather than destruction, and evoke parallels between the architectural, geological or biological structures of the city.

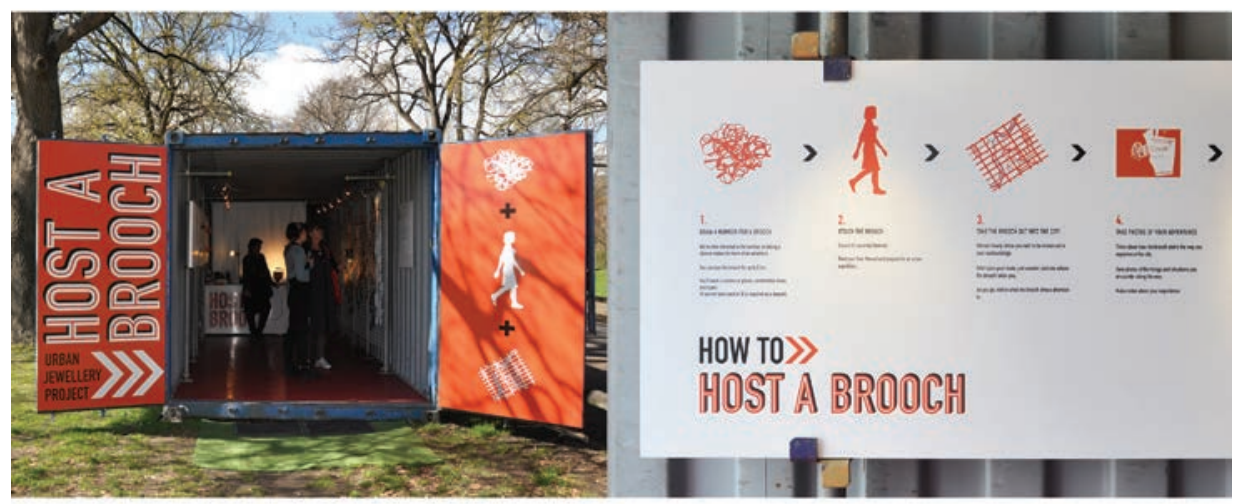

Figure 14. Host A Brooch, Christchurch, 2011.

Photography: Jacqui Chan 
Host A Brooch operated over six weekends from a shipping container placed near the city centre, and it was based on the model of a bike-share system. The public could borrow a brooch for a two-hour unguided wander through the streets, and lenders were briefed to notice what the work drew attention to and take photos. This time wearers were explicitly directed so as to encourage them to pay attention to their surroundings, and the brooches were selected by lucky-dip to eliminate personal preferences or intentions for wearing - which I explained might uphold habitual ways of seeing the city. The bike-share analogy allowed for the pragmatic proposition that, like a riding a bike, attaching this 'thing' to your body and wandering into the city might alter one's experience of the city: through different routes, speeds, or encounters. Afterwards, I downloaded wearer's photos, and asked them to describe their experience verbally and through written feedback.

Once again, what emerged was different from what I had anticipated. Surprisingly, given the circumstances, people reported uplifting experiences, enjoying 'finding beauty in what remains' and having 'permission to see things differently, and act more boldly'. ${ }^{11}$ The brooches produced wide-ranging connections, from earthquake wreckage, road cones and signage, to bare winter trees and spring flowers. ${ }^{12}$
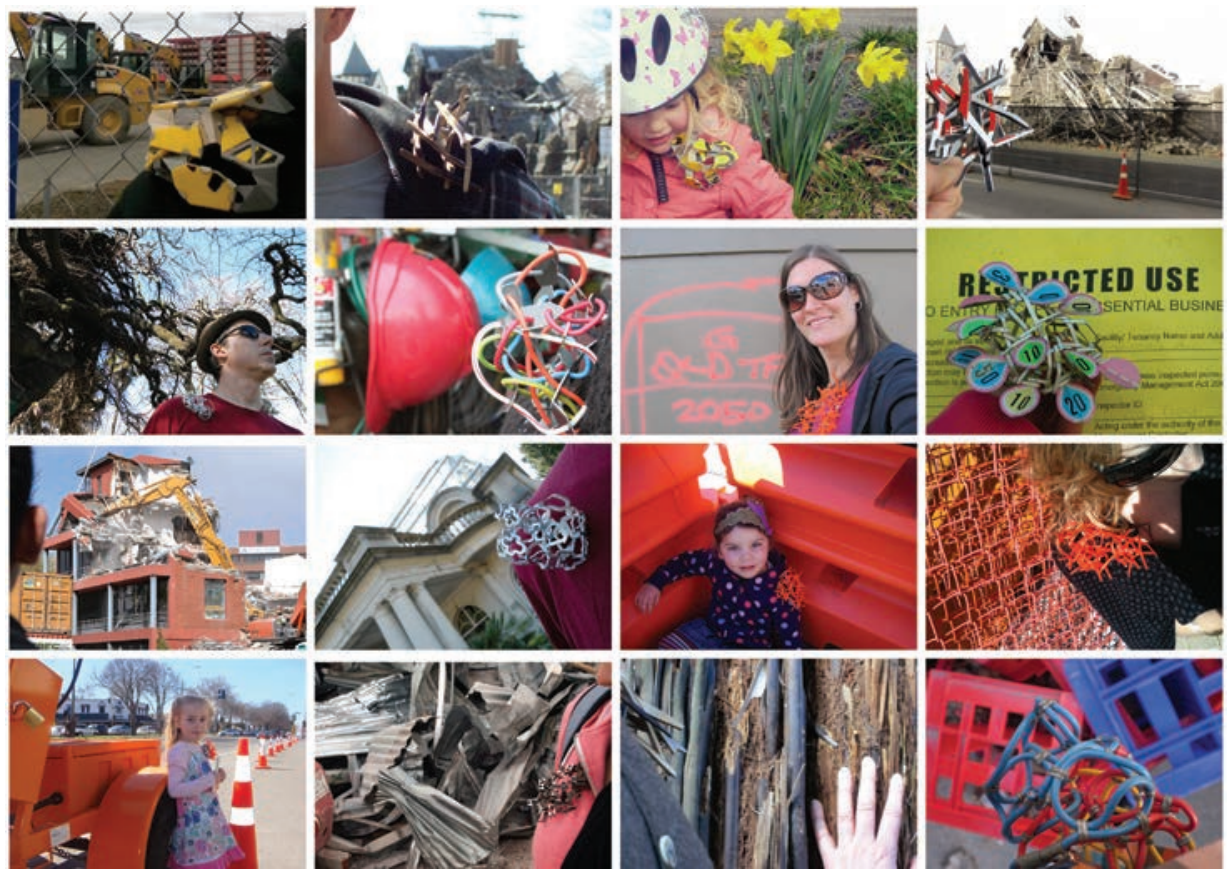

Figure 15. Host A Brooch, Christchurch, 2011.

Photographs provided by participants

11 Participant's written feedback.

12 For full details see http://www.hostabrooch.blogspot.com 
I had hoped the project might spark thinking about the city's process of transformation, and while it did for some, I was surprised that the majority reported noticing colours, shapes, or materials that correlated to the brooch. At the time, these responses seemed superficial, so I tried to coax more thoughtful insights: What kinds of relations did you notice? How did these affect your thinking about the city? But, the prevalence of such responses forced me to think further, and I realised these sensory connections pointed to a different kind of engagement with the city.

The comments seemed superficial precisely because - as Erwin Straus observes - sensation is an immersive state of 'being-with-the-world' that precedes perception and thinking, and the delineation of self from world. He writes:

In the sensory experience, there unfolds both the becomings of the subject and the happenings of the world ... In sensing, both self and world unfold simultaneously for the sensing subject; the sensing being experiences himself and the world, himself in the world, himself with the world" (Straus 1963, cited in Bogue 2003: 116-17).

I noted myself while 'test-driving' a brooch, it was impossible to think about relations while absorbed in the unfolding experience. Rather than prompting thinking, wearing induced an immersive nondual experience that intensified awareness of my surroundings, and expanded my habitual umwelt or bubbleworld.

While most people found such an experience stimulating or enchanting, some found it confronting. For example, one woman described her experience as 'quite disturbing' and filled her with a sense of 'sadness and horror'. She explained that she usually stayed optimistic by only looking at the flowers, trees and standing buildings, but her daughter's orange brooch alerted her to what she ordinarily tried to ignore: orange barricades, road cones and markers of destruction. Another man took the same brooch into the park and had what he called a 'negative experience'. He associated the exuberant brooch with earthquake wreckage and felt it an unwanted intrusion in the happy scene in the park. Their emotional responses were triggered by this shift from their habitual, self-preserving ways of engaging the city.

Another unanticipated outcome was the active and performative encounters the project provoked. In order to document connections between the brooch, body, and things noticed, wearers manoeuvred into unusual positions interacting inventively with their surroundings: leaning on or crouching beside things progressed to lying on barricades and machinery, and more theatrical responses. 

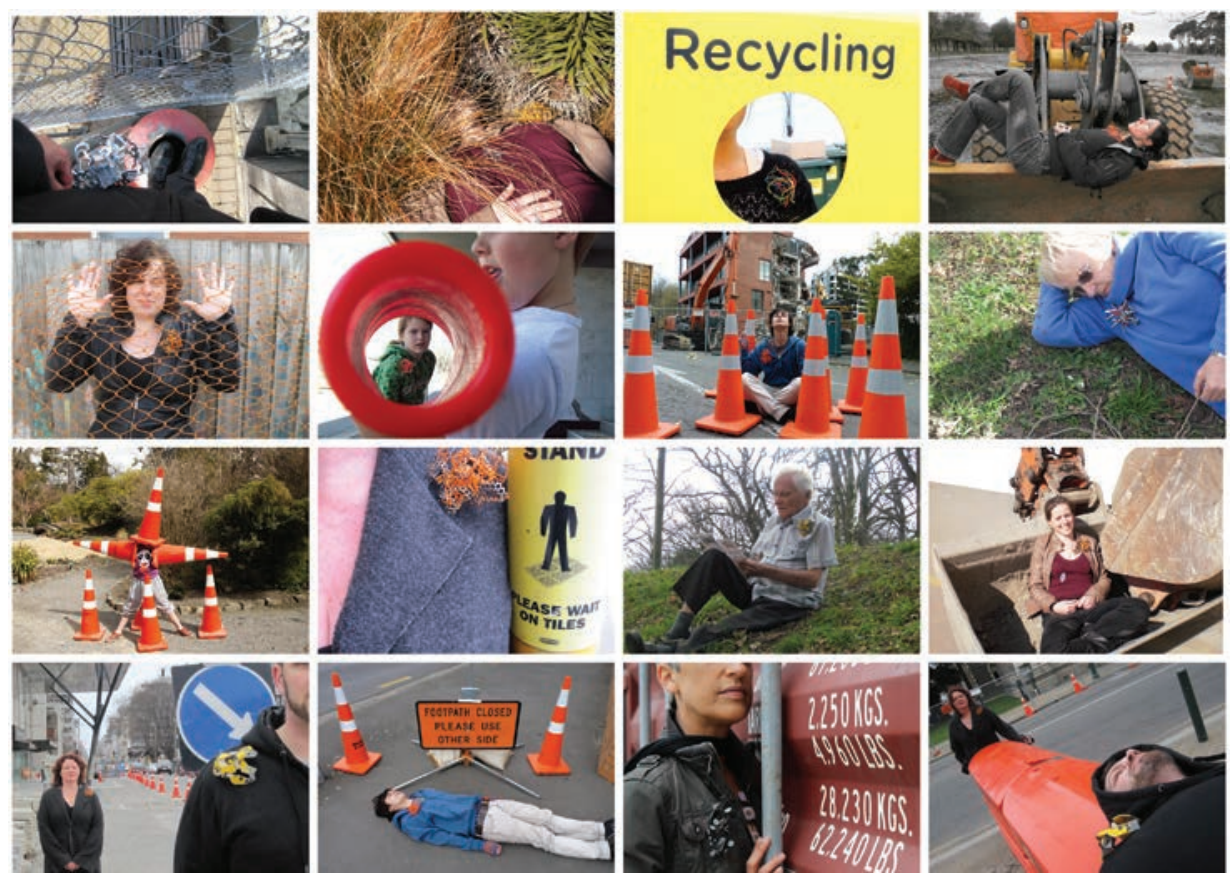

Figure 16. Host A Brooch, Christchurch, 2011.

Photographs provided by participants

This showed that the project evolved from 'testing' the flow-on effects of wearing jewellery in the city, to become a platform for others to reconnect with and reoccupy the changing city. Through this project I came to realise that colourising someone's experience, fostering a state of wonderment or provoking interactions with the city was a radical thing for jewellery to do. Of course, it was not solely the brooch, but the artefact acted as a catalyst for these new experiences.

This wider social effect recalls Jane Bennett's notion of 'ethical energetics', in which she insists that the capacity for enchantment - being captivated by the world rather than fearing it - is a motivating force for facing the painful challenges of a changing and unjust world (Bennett 2001: 160). Although she refers to ethical projects, in Christchurch such motivation was necessary simply to endure the upheaval and participate in the slow process of renewal. Local writer Sally Blundell writes of the contribution such projects make during this time of transition:

These ephemeral interventions precipitate a necessary break from the loss and trauma of the recent past and the wearyingly insistent issues (insurance, investment, 'horizontal infrastructure') of the present ... In Christchurch we patrol the boundaries of a cityscape made strange in the scale of its architectural erasure, peering, staring, again and again. In tripping this wire of 'catatonic' inertia, however, Gap Filler, Greening 
craft + design enquiry

Spaces and Host A Brooch successfully instigate a transformation from the impassive stance of the witness to the more optimistic role of the participant. (Blundell \& Banbury 2012: 28)

\section{Conclusion}

By way of a conclusion, through these projects the question of how jewellery can engage the city in terms of emergence has yielded an approach to jewellery practice that fosters an embedded and reciprocating relation with the urban context. The logic of the saprophyte has enabled the city to be encountered as the dynamic material ecology composed through continual flows and transformations of materials (including bodies) and exposed not only to human, but ecological and geological forces.

Within this extended site, the analogy of the saprophyte has enabled me to situate my jewellery practice within its materials-flows, diverting and transforming materials and recirculating them anew. This has developed a relation between jewellery practice and the urban milieu that works in terms of emergence, rather than representation, entering into the midst of a situation, processing aspects of its material conditions to produced a third thing. The resulting jewellery does not seek to resemble the urban context in its material form, but activates it by re-entering its flows of bodies.

In turn, wearing has become a vital part of jewellery practice, approached as an extension of the saprophytic making processes and feeding nutrients back into the system. The projects allowed wearers to engage in wearing as an encounter and an experience that affects us and connects us with our surroundings. What emerged through the wearing projects exceeded what I anticipated jewellery could do: inciting interactions with the city, activating sensory awareness, and making new aspects of a situation perceptible. This shifted people beyond habitual modes for engaging the city to incite immersive experiences, turning attention to the overlooked and sparking lively participation in the urban milieu. As such, this practice-led research not only enriched thinking about jewellery's relations with the city, but also made a wider contribution to the city.

Jacqui Chan is a contemporary jeweller from New Zealand, currently based in Melbourne. She is currently undertaking a $\mathrm{PhD}$ at RMIT University exploring jewellery's relation with the city. Her approach to jewellery is influenced by her background in architecture. Her work has been included in exhibitions in New Zealand, Australia and Europe, and is part of public collections in New Zealand. 


\section{References}

Albanese, F. 2008, 'In praise of saprophytes', Domus, no. 917, viewed 21 Aug. 2008, http://www.flavioalbanese.com/917\%20uk.aspx?Layout=pop

Bennett, J. 2001, The Enchantment of Modern Life: Attachments, crossings and ethics, Princeton University Press.

- - 2004, 'The force of things: Steps toward an ecology of matter', Political Theory, pp. 347-72, viewed 16 Sept. 2009, http://ptx.sagepub.com/cgi/ content/abstract/32/3/347

Blundell, S. \& Banbury, G. 2012, 'Two takes on Christchurch: The city transformed', Art New Zealand, no. 142, pp. 23-29.

Bogue, R. 2003, Deleuze on Music, Painting, and the Arts, New York: Routledge.

Bourriaud, N. 2002, Relational Aesthetics, Dijon: Les Presses du réel.

Canguilhem, G. 2001, 'The living and its milieu' Grey Room no. 3, pp. 6-31.

DeLanda, M. 1997, A Thousand Years of Nonlinear History, New York: Zone Books.

- - 2011, Philosophy and Simulation: The emergence of synthetic reason, London; New York: Continuum.

Deleuze, G. 1992, 'Ethology: Spinoza and us', in J. Crary \& S. Kwinter (eds), Incorporations, New York: Zone, pp. 625-33.

- - 2004, Francis Bacon: The logic of sensation, Minneapolis: University of Minnesota Press.

Deleuze, G. \& Guattari, F. 2004, A Thousand Plateaus: Capitalism and schizophrenia, London: Continuum.

Ednie-Brown, P. 2008, 'Plastic super models: Aesthetics, architecture and the model of emergence', Fibreculture Journal, vol. 12, viewed 10 Sept. 2009, http://journal.fibreculture.org/issue12/issue12_ednie-brown.html.

Grosz, E. 1995, 'Bodies-cities', in Space, Time and Perversion: Essays on the politics of bodies, New York; London: Routledge, pp. 103-10.

Mercier, G. 2009, 'Vidal de la Blache, P.', in R. Kitchin \& N. Thrift (eds), International Encyclopedia of Human Geography, Oxford: Elsevier.

Protevi, J. 2006, 'Deleuze, Guattari and emergence', Paragraph: A Journal of Modern Critical Theory, vol. 29, no. 2, pp. 19-39.

Simmel, G. 1950, 'Adornment', in The Sociology of George Simmel, Glencoe, Illinois: The Free Press. 
craft + design enquiry

Uexküll, J.V. 2001, 'An introduction to umwelt' Semiotica vol. 134, no. 1, pp. $107-10$.

- - 2010, A Foray into the Worlds of Animals and Humans: With a theory of meaning, Minneapolis; London: University of Minnesota Press. 